\title{
"Candidatus Microthrix parvicella," a Filamentous Bacterium from Activated Sludge Sewage Treatment Plants
}

\author{
LINDA L. BLACKALL, ${ }^{*}$ HELEN STRATTON,${ }^{2}$ DEBBIE BRADFORD,${ }^{1}$ THERESE DEL DOT, ${ }^{1}$ \\ CAMILLA SJÖRUP, ${ }^{1}$ ELIZABETH M. SEVIOUR, ${ }^{2}$ AND ROBERT J. SEVIOUR ${ }^{2}$ \\ Centre for Bacterial Identification and Diversity, Department of Microbiology, The University of \\ Queensland, Brisbane, Queensland 4072, ${ }^{1}$ and Biotechnology Research Centre, \\ La Trobe University, Bendigo, Victoria $3550,{ }^{2}$ Australia
}

\begin{abstract}
"Candidatus Microthrix parvicella" is a filamentous bacterium that grows with great difficulty in cultures from the mixed liquor of activated sludge sewage treatment plants. It is gram positive, and the ultrastructure of its cell walls has been determined to be of the gram-positive type by electron microscopical examination. Phylogenetically, it is a deep-branching member of the subphylum actinomycetes within the gram-positive phylum of the domain Bacteria. As for phenotypic features, it is known that the organism contains polyphosphate inclusions and that it is catalase positive. In mixed cultures in activated sludge plants and in pure culture in the laboratory, it has a characteristic and distinctive winding filamentous morphology, with filaments hundreds of micrometers long.
\end{abstract}

\begin{abstract}
"Microthrix parvicella" is a filamentous bacterium found in activated sludge sewage treatment plants, where it causes solids separation problems known as foaming and bulking (7). It is found in these plants throughout the world, and when surveys of the solids separation problems are carried out, this bacterium features near the top of the list of causative organisms. " $M$. parvicella" is notorious in the wastewater industry because of its problem-causing properties. Although some researchers isolated it with apparent ease $(4,5,15,17)$, in recent years it has eluded many, as evidenced by active discussion at the International Association on Water Quality conference on Microorganisms in Activated Sludge and Biofilm Processes (Paris, France [12]) and the workshop on Microbial Ecology in Wastewater (Stuttgart, Germany [9]).
\end{abstract}

For a summary of the information on "M. parvicella", the work of Blackall et al. (2) should be consulted. However, much information on the attempts to isolate this organism is not included in that publication. We have attempted to obtain " $M$. parvicella" in axenic culture for 12 years. During this time it is estimated that more than 700 " $M$. parvicella" filaments have been micromanipulated. A wide range of media which were incubated in a range of atmospheres and temperatures was evaluated. In our experience, the " $M$. parvicella"-specific, chemically defined medium of Slijkhuis (14) has never supported the growth of any micromanipulated filaments nor that of any isolates of " $M$. parvicella" obtained from other media. Of all the media reported to support the growth of filamentous bacteria from activated sludge, only freshly prepared R2A (13) and modified NTM $(2,8)$ have been able to sustain " $M$. parvicella" growth, and these media are not universally successful. Atmospheres tested with a range of media included $90 \% \mathrm{CO}_{2}$ plus $10 \% \mathrm{H}_{2}$ and the microaerophilic conditions generated by so-called candle jars. Neither condition increased isolation success, nor did either accelerate the growth rates of isolates. Filaments of " $M$. parvicella" were manipulated to other media and incubated at natural atmosphere and 20 to $22^{\circ} \mathrm{C}$. These media included (i) liquid and solid (1.5\% agar) media based on activated sludge (autoclaved, filtered mixed liquor; autoclaved, unfiltered mixed liquor; and unautoclaved, filtered mixed li-

* Corresponding author. Phone: 61733654645 . Fax: 61733654620. Electronic mail address: blackall@florey.biosci.uq.edu.au. quor); (ii) $\mathrm{R} 2 \mathrm{~A}$ (13) prepared at $\mathrm{pH}$ values from 5 to 9 at increments of $1 \mathrm{pH}$ unit, R2A with agar concentrations ranging from 0.4 to $1.0 \%$ in $0.2 \%$ increments, and $\mathrm{R} 2 \mathrm{~A}$ with a range of detergents, including sodium dodecyl sulfate, Triton X-100, Tween 20, Tween 40, Tween 60 , and Tween 80 . Solutions of 4 $\mathrm{g} /$ liter of the detergents were prepared, and $1 \mathrm{ml}$ was spread on to the agar media prior to micromanipulation of filaments to the media; (iii) LMNS agar, WYE agar, and YCED agar from the work of Crawford et al. (3); and (iv) supplementation of R2A and modified NTM with Oxoid Legionella growth supplement containing cystine and ferric phosphate.

None of the media cited above were able to support the growth of micromanipulated " $M$. parvicella" filaments. Furthermore, we have isolated " $M$. parvicella" from only 6 of about 100 plants where they were morphologically identified and from which isolation was attempted. We have been able to maintain isolates from two plants. A problem that occurs from time to time is the overgrowth of the micromanipulated filaments by other more rapidly growing bacteria that were accidentally manipulated with the filaments. This is exacerbated by the extremely slow growth of " $M$. parvicella", during which macroscopically visible colonies take more than four weeks to appear. However, the biggest problem that we experience is simply lack of growth of the manipulated filaments. We speculate that filaments seem to initially grow but then become moribund, possibly because of the buildup of some toxic product of metabolism. We do not suspect nutrient depletion as the cause of growth limitation.

Turning to molecular biological methods, we obtained foam samples from activated sludge plants and employed micromanipulation techniques to obtain a large number of " $M$. parvicella" filaments that were then used for cell lysis and amplification of the DNA coding for 16S rRNA (rDNA) with conserved bacterial primers. However, this attempt was unsuccessful. This approach was used to obtain the $16 \mathrm{~S}$ rDNA from Epulopiscium fishelsoni (1).

We were then successful in obtaining two pure cultures of " $M$. parvicella" by micromanipulating filaments to growth media. DAN1-3 (from Dandenong Sewage Treatment Plant, Victoria, Australia) grows on modified NTM (2), while Ben43 (from Bendigo Sewage Treatment Plant, Victoria, Australia) grows on freshly prepared R2A. A small amount (ca. $1 \mathrm{~mm}^{3}$ ) of the pure culture of " $M$. parvicella" DAN1-3 was used to 


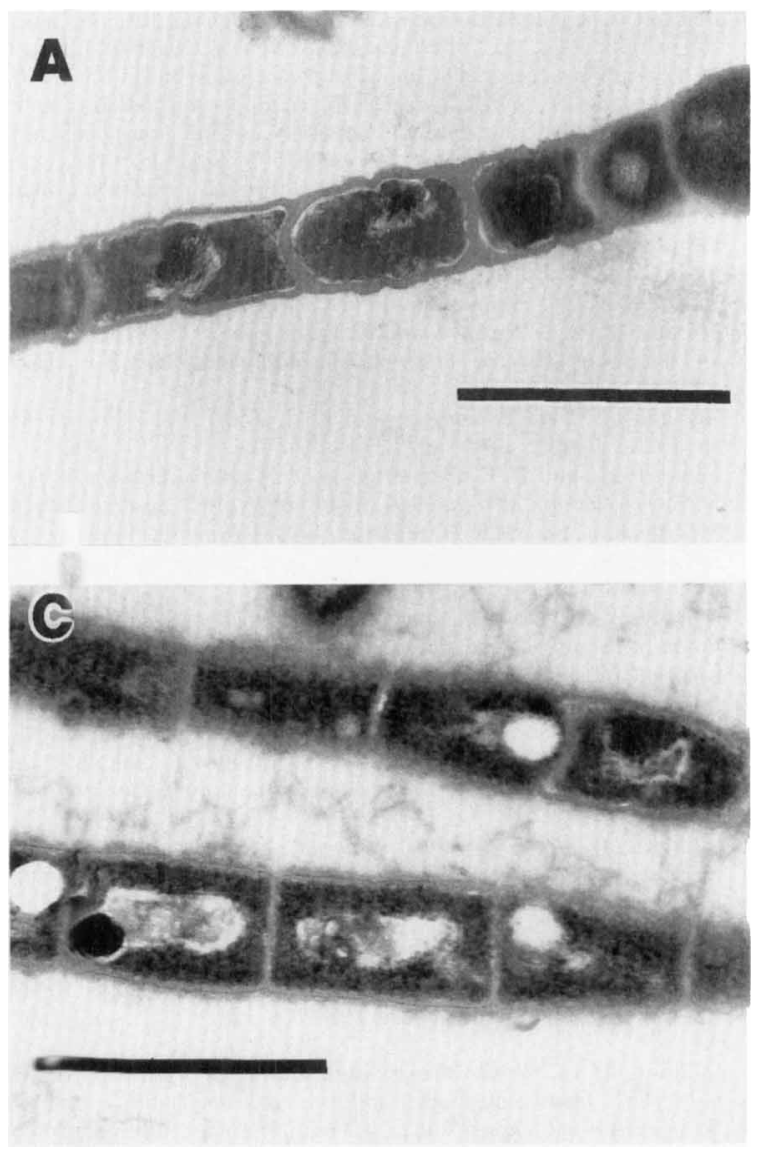

obtain its 16S rDNA sequence (X82546) and to phylogenetically classify it as a deep-branching member of the actinomycetes subphylum (2). Later, we found the $16 \mathrm{~S}$ rDNA sequence (X89774) of Ben43 to be nearly identical to that of DAN1-3. The most similar organism by sequence comparison is a thermophilic, gram-indeterminate, sulfur-oxidizing bacterium known as strain TH3. In addition, we have prepared a $16 \mathrm{~S}$ rDNA clone library from activated sludge from Orange, New South Wales, Australia. This sludge contained large numbers of bacteria morphologically identified as " $M$. parvicella". Preliminary examination of the library revealed two clones with sequences nearly identical to the $16 \mathrm{~S}$ rDNA sequences of DAN1-3 and Ben43 (clone 6, X89560; clone 17, X89561). Our conserved gene sequence data therefore indicate that the same organism is present in three distinct sites.

We have prepared ultrathin sections (6) of the pure culture Ben43 and of sludge containing filaments morphologically identified as "M. parvicella" (from Orange, New South Wales, Australia). The material was fixed in $3 \%$ glutaraldehyde in 0.1 $\mathrm{M}$ cacodylate buffer and then in $1 \% \mathrm{OsO}_{4}$ in $0.1 \mathrm{M}$ cacodylate buffer. The samples were washed, dehydrated in graded solvent solutions, and embedded in Spurr's resin. Ultrathin sections were cut on an LKB Ultramicrotome, stained with $5 \%$ uranyl acetate in $50 \%$ methanol and Reynold's lead citrate. The cells were viewed in an Hitachi $\mathrm{H}-800$ transmission electron microscope. Figure 1 shows that the cells of " $M$. parvicella" have distinctly gram-positive cell walls, with cellular dimensions ranging from 0.5 to $0.9 \mu \mathrm{m}$ by 0.4 to $0.5 \mu \mathrm{m}$. No spores were observed in these preparations.

"M. parvicella" is routinely identified in mixed liquor and

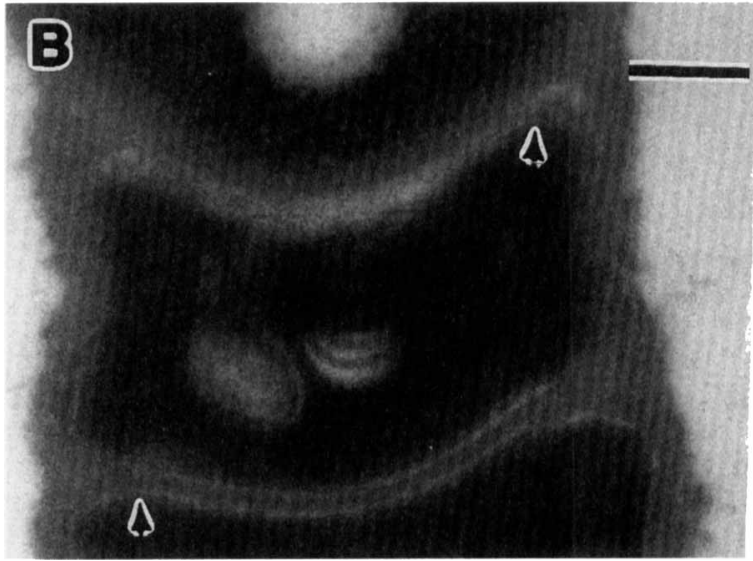

FIG. 1. Transmission electron micrographs of ultrathin sections of "Candidatus Microthrix parvicella". (A) A part of a filament of the pure culture Ben43. (B) A close-up of a cell of Ben43 pure culture showing the cytoplasmic membrane (arrows) and thick gram-positive cell wall. (C) Two filament fragments from the mixed liquor from the Orange Sewage Treatment Plant, New South Wales, Australia. Bar (A and C), $1 \mu \mathrm{m}$; bar (B), $0.1 \mu \mathrm{m}$.

foams from activated sludge plants. Since it cannot be readily grown to pure culture, the only attributes that are used for identification are in situ morphology and staining reactions. The filaments are classically gram positive. However, some of the cells that comprise the filaments are gram negative, and van Veen (17) suggested that these were empty, autolyzed cells. The Neisser stain (7) that is used to show intracellular inclusions of polyphosphate is positive for " $M$. parvicella" $(2,4$, 17). Individual cells in the filaments cannot be seen by light microscopy. Electron microscopical studies showed that the length and diameter of individual cells varied from 0.7 to 1.5 $\mu \mathrm{m}$ and 0.3 to $0.7 \mu \mathrm{m}$, respectively (17). Our data largely concur with those of Jenkins et al. (7) and van Veen (17). Farquhar and Boyle (5), van Veen (17), and Eikelboom (4) all obtained pure cultures of " $M$. parvicella". Slijkhuis (14) and Slijkhuis et al. (16) also obtained pure cultures, determined carbon utilization patterns, and described the requirement by

TABLE 1. Codified record for "Candidatus Microthrix parvicella"

\begin{tabular}{|c|c|}
\hline Feature & \\
\hline \multicolumn{2}{|c|}{ 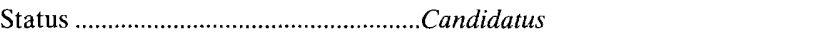 } \\
\hline \multicolumn{2}{|c|}{ Vernacular epithet ................................"Microthrix parvicella" } \\
\hline \multicolumn{2}{|c|}{$\begin{array}{r}\text { Phylogenetic lineage ............................Subphylum, actinomycetes; gram- } \\
\text { positive phylum; domain, Bacteria }\end{array}$} \\
\hline \multicolumn{2}{|c|}{ 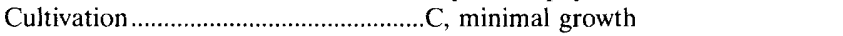 } \\
\hline \multicolumn{2}{|c|}{ Gram reaction......................................G+ } \\
\hline \multicolumn{2}{|c|}{ 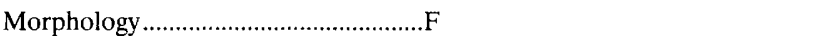 } \\
\hline \multicolumn{2}{|c|}{$\begin{array}{c}\text { Basis of assignment ................................ } \\
\text { X82546), M }\end{array}$} \\
\hline \multicolumn{2}{|c|}{$\begin{array}{l}\text { Specific identification of } \\
\text { morphotype .......................................Morphological identification }\end{array}$} \\
\hline \multicolumn{2}{|c|}{$\begin{array}{c}\text { Habitat, association, or host ................FL (activated sludge sewage treat- } \\
\text { ment plant) }\end{array}$} \\
\hline \multicolumn{2}{|c|}{$\begin{array}{r}\text { Metabolism and unusual features ...... Characteristic, irregular and winding } \\
\text { coiled filaments, catalase positive, } \\
\text { polyphosphate inclusions }\end{array}$} \\
\hline \multicolumn{2}{|c|}{ Growth temperature ............................M } \\
\hline \multicolumn{2}{|c|}{$\begin{array}{l}\text { Source } \\
\text { activated sludge sewage treatment } \\
\text { plants }\end{array}$} \\
\hline uthors ............................. & \\
\hline
\end{tabular}

\footnotetext{
"See references 10 and 11 .
} 
"M. parvicella" for reduced nitrogen and sulfur in the growth media. None of the above-mentioned authors was able to store the bacterium. We have not been able to obtain enough biomass of our Australian isolates of " $M$. parvicella" to confirm the biochemical results. However, we are in the process of developing in situ hybridization probes for " $M$. parvicella" based upon our $16 \mathrm{~S}$ rDNA sequences. We will then be able to survey sewage treatment plants to determine whether filaments identified as " $M$. parvicella" are the same as DAN1-3 and Ben43.

Currently, not enough phenotypic data exist for any " $M$. parvicella" strain to validly name the organism. We are still striving to grow the bacterium in sufficient amounts so that distinguishing phenotypic and chemotaxonomic data for " $M$. parvicella" can be determined. Since we and others have not succeeded in addressing the growth limitations of " $M$. parvicella" in the last decade, we are not confident of a rapid solution. Therefore, we propose to name the organism "Candidatus Microthrix parvicella" (Table 1), employing the proposal of Murray and Schleifer (10) and the recommendation of the International Committee on Systematic Bacteriology (11). The word "microthrix" must be in the name, because the organism is well known in the wastewater industry by this vernacular. Communication on this major environmental, problem-causing bacterium must not be hindered by changes in the familiar name.

We thank Rick Webb and Margaret Lindsay for assistance with electron microscopy, Erko Stackebrandt for useful discussion about the Candidatus concept, and Philip Hugenholtz for extensive "Microthrix" discussions and for reviewing the manuscript.

\section{REFERENCES}

1. Angert, E. R., K. D. Clements, and N. R. Pace. 1993. The largest bacterium. Nature (London) 362:239-241.
2. Blackall, L. L., E. M. Seviour, M. A. Cunningham, R. J. Seviour, and P. Hugenholtz. 1994. "Microthrix parvicella" is a novel, deep branching member of the actinomycetes subphylum. Syst. Appl. Microbiol. 17:513-518.

3. Crawford, D. L., J. M. Lynch, J. M. Whipps, and M. A. Ousley. 1993. Isolation and characterization of actinomycete antagonists of a fungal root pathogen. Appl. Environ. Microbiol. 59:3899-3905.

4. Eikelboom, D. H. 1975. Filamentous organisms observed in activated sludge Water Res. 9:365-388.

5. Farquhar, G. J., and W. C. Boyle. 1971. Identification of filamentous microorganisms in activated sludge. J. Water Pollut. Control Fed. 43:604-622.

6. Hayat, M. A. 1993. Stains and cytological methods. Plenum Press, New York.

7. Jenkins, D., M. G. Richard, and G. T. Daigger. 1993. Manual on the causes and control of activated sludge bulking and foaming. Lewis Publishers, New York.

8. Kocianova, E., C. F. Forster, and R. J. Foot. 1994. What is Microthrix parvicella? J. Appl. Bacteriol. 76:301-306.

9. Lemmer, H., and H.-C. Flemming. 1994. Microbial ecology in wastewater. Society of General and Applied Microbiology, Inc., Stuttgart, Germany.

10. Murray, R. G. E., and K. H. Schleifer. 1994. Taxonomic notes: a proposal for recording the properties of putative taxa of procaryotes. Int. J. Syst. Bacteriol. 44:174-176.

11. Murray, R. G. E., and E. Stackebrandt. 1995. Taxonomic note: implementation of the provisional status Candidatus for incompletely described procaryotes. Int. J. Syst. Bacteriol. 45:186-187.

12. Pujol, R. 1994. Microorganisms in activated sludge and biofilm processes Water Sci. Technol. 29:1-391.

13. Reasoner, D. J., and E. E. Geldreich. 1985. A new medium for the enumeration and subculture of bacteria from potable water. Appl. Environ. Microbiol. 49:1-7.

14. Slijkhuis, H. 1983. Microthrix parvicella, a filamentous bacterium isolated from activated sludge: cultivation in a chemically defined medium. Appl. Environ. Microbiol. 46:832-839.

15. Slijkhuis, H., and M. H. Deinema. 1982. The physiology of Microthrix parvicella a filamentous organism isolated from activated sludge, p. 75-83. In B. Chambers and E. J. Tomlinson (ed.), Bulking in activated sludge: preventative and remedial methods. Ellis Horwood Ltd., Chichester, United Kingdom.

16. Slijkhuis, H., J. W. van Groenestijn, and D. J. Kylstra. 1984. Microthrix parvicella, a filamentous bacterium from activated sludge: growth on Tween 80 as carbon and energy source. J. Gen. Microbiol. 130:2035-2042.

17. van Veen, W. L. 1973. Bacteriology of activated sludge, in particular the filamentous bacteria. Antonie van Leeuwenhoek 39:189-205. 